\title{
USING ABACUS AND BUNDLES OF STICK TO HELP BASIC TWO (2) PUPILS TO ADD TWO AND THREE-DIGIT NUMBERS: AN ACTION RESEARCH OF GHANA NATIONAL COLLEGE BASIC SCHOOL, CAPE COAST, CENTRAL REGION, GHANA
}

\section{Dennis Offei Kwakye', Ernest Kwaku Ofosu ${ }^{2}$, Sulemana Karim ${ }^{3}$, Yusif Zacharia ${ }^{4}$, Zunurain Zakari $^{5}$ and Emmanuel Asemani ${ }^{6}$}

${ }^{1}$ Mathematics Tutor, Department of Mathematics and ICT, Enchi, College of Education, P. O. Box 44, Enchi, Western-North Region, Ghana.

Email: dokwakye@enchicoe.edu.gh,denniskkdo@gmail.com

${ }^{2}$ Mathematics Tutor, Department of Mathematics, SDA College of Education, P. O. Box 18, Asokore-Koforidua, Eastern Region, Ghana. Email: ofosu_kwaku@ rocketmail.com

${ }^{3}$ Mathematics Tutor, Department of Mathematics and ICT, Gambaga College of Education, P.

O. Box 33, Gambaga, Ghana. Email: sulemanakarim@gmail.com

${ }^{4}$ Mathematics Tutor, Department of Mathematics and ICT, Tumu College of Education, P. O. Box 19, Tumu, Upper-West Region, Ghana. Email: yusifdanzacharia@gmail.com

${ }^{5}$ Mathematics Tutor, Mathematics and ICT Department, Methodist College of Education, P. O. Box 50, Akyem-Aboabo, Oda, Eastern Region, Ghana.

Email: zakarizunurain76@gmail.com

${ }^{6}$ Mathematics Tutor, Department of Mathematics and ICT Education, Presbyterian Women's College of Education, P. O. Box 19, Akuapem Aburi, Eastern Region, Ghana.

Email: easemani@pwce.edu.gh, easemani2018@gmail.com

\begin{abstract}
The purpose of this study was to use Abacus and Bundles of stick as Instructional Materials or Teaching Learning Materials (TLMs) to improve the addition of two- and three-digit numbers among Basic Two (2) Pupils of Ghana National College Basic School, Cape Coast, Central Region, Ghana. Action research design was used for the study. Evaluation Test (Pre-Test and Post-Test) were used to gather data on the pupils. The population was thirty-four (34) and the sample used for the study was fourteen (14) pupils. Pre-Test was used to assess the pupil's performance to identify their strength and weakness for the necessary interventions to be used to solve that problem. Post-Test was used to gather results and compare the effectiveness of the use of Abacus and Bundles of stick in solving addition of two- and three-digits numbers in mathematics. Simple percentage count was employed by the researcher to display the results and findings. It was found out from the study that, appropriate materials like Bundles of sticks and Abacus should be encouraged and be used in primary schools more especially at the Lower Primary levels (Early Grade levels) to teach for the pupils to overcome their difficulties in solving addition problems involving two- and three-digits numbers.
\end{abstract}

KEYWORDS: Abacus, Bundles of Stick, Two and Three-Digit Numbers, Teaching and Learning Materials, Addition, Early Grade 


\section{INTRODUCTION}

\section{Background of the Study}

Mathematics as a subject in the school curriculum is compulsory, both at the Basic and Senior High Schools levels. It also plays leading and important roles in all aspects of human endeavour. The use of mathematics is found in many areas of real-life situations. The field of management, business and marketing are not exceptions. In the history of education, mathematics has held its leading position among all other school subjects because it has been considered as an indispensable tool in this technological fast-growing world.

The foundation blocks of mathematics are made up of the concepts of additions and subtractions. Therefore, no building of mathematics can be put up without the solid basic foundation concept, which is addition. It is one of the most important concepts of mathematics and ones inability to do simple addition fails to climb the academic ladder of education to its topmost height. The researcher had the opportunity to help the final year students who were preparing for their Basic Education Certificate Examination. It was then that the researcher met these Basic Two pupils, interact and help solve certain pressing issues and problems facing pupils' education in the basic school.

The researcher observed that, some pupils in Class Two (2) were unable to do simple addition of two- and three-digits numbers. When the Class Teacher and the previous Class Teacher were consulted, they both said that, much effort had been put in, in solving the problem but they have all proved futile. When the problem was identified, the researcher took it upon herself to delve into the root of the pupils' inability to solve problems in addition of two- and three-digits numbers.

\section{Statement of the Problem}

The researcher understudied the Basic Two (2) Pupils of Ghana National College Basic School during the visit. Upon careful observation and test conducted by the researcher during that period revealed that, the pupils were unable to do simple addition involving two- and three-digits numbers.

This generates results in low performance of pupils in mathematics. The problem therefore necessitated a thorough investigation into their causes in order to find remedial measures for them. Hence, this study.

\section{Purpose of the Study}

The purpose of this study is to help Basic Two (2) Pupils of Ghana National College Basic School additions involving two- and three-digits numbers in mathematics through the use of Abacus and Bundle of sticks (instructional materials or Teaching Learning Materials (TLMs)).

Also, the purpose is to identify the effect of using Abacus and Bundle of sticks in teaching and learning addition of two- and three-digit numbers.

\section{Research Questions}

This research seeks to find answers to the following questions; 
1. How can the use of instructional materials help Basic Two (2) pupils of Ghana National College Basic School to add two- and three-digit numbers using the Abacus and or the Bundle of sticks?

2. What are some of the effects of using instructional materials in enhancing proper addition of two- and three-digit numbers?

\section{Significance of the Study}

The outcome of this research will be of benefit to the Basic Two (2) Pupils of Ghana National College Basic School. The study will also benefit the teachers in the school as to how to select an appropriate instructional material when teaching addition. Also, it will be of importance to policy makers such as Curriculum Research Development Division (CRDD) of Ghana Education Service on how to select topics on addition for pupils in our schools.

The outcome of this research will enable pupils or learners to have vast knowledge and understanding about instructional materials to enhance their performance when a question is given after a lesson has been taught in class.

\section{Delimitations}

This research is focused on the use of instructional materials to improve on difficulty in addition among Basic Two (2) Pupils of Ghana National College Basic School, Cape Coast in the Central of Ghana.

\section{Limitations}

This project was conducted at Ghana National College Basic School with Class Two (2) Pupils who have difficulties in addition of two- and three-digit numbers. The study would have covered the whole district primary pupils but due to limited time, financial constraints, transportation and inadequate instructional materials, the researcher was limited to only Basic Two (2) Pupils of Ghana National College Basic School at Cape Coast Metropolitan in the Central Region of Ghana.

\section{Organization of the Study}

The first chapter of this study covers the introductory section. It spells out the background of the study, statement of the problem, purpose of the study, research questions, significance of the study, delimitation, limitation and organization of the study.

Chapter two deals with review of related literature which consists of overview, written materials and opinions of experts in the field understudy. It also talks about the meaning of mathematics, the meaning of addition, instructional materials (Teaching Learning Materials (TLMs)) and their role in teaching and learning mathematics, methods of teaching mathematics, the use of Abacus and Bundle of sticks in addition with its associates.

Chapter three, which is the methodology, entails the research design, population, sample and sampling technique, instrumentations, Pre-Tests, Interventions, Post-Tests, data collection procedure and data plan. 
Chapter four is the analysis and discussion of findings. It also represents the results on the study conducted.

Chapter five is the conclusive part of the research which consists of summary, suggestions, conclusion and recommendations.

\section{LITERATURE REVIEW}

\section{The Meaning of Mathematics}

The subject Mathematics does not have a single definition which has been given and accepted worldwide. Several people have drawn definitions in the manner that they perceived it. It is against this background that Addae (2006) came out that mathematics is "quietly fragment without the operation of addition and its reciprocal subtraction".

From the New Cambridge Advanced Learner's Dictionary, "mathematics is the study of numbers, shapes and space using reason and usually with a special system of symbols and rules for organizing them". It also pointed out that mathematics includes algebra, arithmetic, and geometry. However, this explanation can be affirmed with the appreciation of mathematical knowledge in the construction of tools and shelter in the early years.

Mathematics is deemed as the main switch behind science and technology. Mathematics also plays a vital role in the life of every individual. The impact of mathematics has in the development of the world today cannot be left out, yet a large number of people are afraid to pursue programmes that are mathematically related. Pal (2009) concluded that many difficulties that children face in leaning are rooted in the lack of understanding of lower level concepts and lack of clarity about different rules that are often conflicting and can lead to misconceptions and affect mathematical learning. Acha (2014) concluded that children's learning processes are hindered by limited working memory.

\section{The Meaning of Addition}

According to the Oxford Learner's Advance Dictionary (2001), "Addition is the process of adding two or more numbers of distinct values together to find their totals". Simply put, "Addition refers to the act of putting two or more things together to increase the size, number, amount and so on. Apronti (2001) said, "Addition and Subtraction are the basis of mathematics". He supported Asante (2012) who said that, "the main idea which are mostly used in our daily activities bring to light that almost all the concepts in mathematics are developed out of addition".

For instance, the concept of measurement and algebra are made up of addition. He advised that substantial attention must be given to the methods and teaching techniques as well as teaching aids to enrich its understanding.

From Land (2002), the letter and symbols which denote numbers are the short form of mathematics and for that matter, greater attention should be given to it in order to make pupils understanding permanent so as to foster learning in the classroom. More so, it has been noted that most pupils normally find it very uneasy to cope with addition using Abacus and Bundle of sticks. 


\section{Instructional Materials and their role in Teaching Mathematics}

Instructional materials are the physical objects used in the classroom during teaching and learning. Paksu and Ubuz (2009) found that drama-based instruction had a significant effect on student's achievement and make learning easy and understanding better by providing the opportunity to contextualize geometry concept and problems. Benjamin (2002) stated that, "the use of instructional materials makes unique contributions to improve teaching and learning at all levels". This can be realized through the development of the pupils' manipulative and analytical skills and high level of interest in the learning process.

From a sociocultural perspective on mathematics (Forman, 2003), the teacher must consider not only the instructional materials available but also his or her students' backgrounds, mathematical knowledge, special needs, and culture in implementing a particular curriculum. Regardless of the materials provided by the school, the teacher is the ultimate decision-maker and curriculum developer in the classroom.

Kalejaiye (2004) stated that, "the selection of a variety of teaching aids often follows the choice of methods of teaching mathematics in primary schools". This is because primary school children are at the concrete operational stage - the stage when they learn working with physical objects. The teaching aids will enable them understand better the basic principles of mathematics, such as number relationships, the idea of Abacus and Bundle of sticks among many others.

\section{Methods of Teaching Mathematics}

According to the New Cambridge Advanced Learner's Dictionary, "teaching is the act of given someone knowledge or to instruct or train someone". It continues to explain that "teaching improves someone's future behavior". This indeed attest to the fact that a logical knowledge is not acquired from reading and listening to peoples' talk but to construct from actions on objects. It is also good to use distinct examples and materials when necessary to impact mathematical concepts to learners at all levels.

Mathematics teachers should be abreast with the terminologies, symbols, signs so as to enhance efficient tuition of the subject at all levels and in all spheres of life. With regards to Ansubel et al (2003), it is appropriate to note that, the most important single factor influencing learning is what the learners already know. Therefore, it is essential for teachers to ascertain this and teach pupils at all stages accordingly.

Admittedly, it is clear that pupil's relevant previous knowledge should be traced before any meaningful teaching and learning can take place.

In addition, Davidson et al (2001) expressed that schools could be built, adequate textbooks can be provided but if pupils are not given proper tuition and skills, then, we should be counting numbers backwards on the progress chart. Teachers are to make good use of teaching and learning materials to arouse pupils' curiosity to work on any given activity until he or she is satisfied with the outcome or results.

Habbard (2000) and the great psychologist Jerome Brunner (1995) advocated for the question method of teaching mathematics. They observed that, it is easier for people to fall asleep while reading or listening rather than speaking or writing. This may be one reason why pupils 
are more responsive and more actively involved in classroom when they are made to examine the content of the lesson more closely by the use of questions. Students' answers to questions also enable the teachers to judge their level of understanding and to assess their progress.

Biggs (2000) also stated that, "the choice of a teaching method depends on so many factors such as the level of the class, the ability of the pupils, the nature of the mathematics topic and the facilities available in the school". She suggested that teachers should divide the class into groups of five or six of about the same ability and teach them in groups. This procedure will enable the teacher to attend to the weak groups and also give the more able groups more challenging task.

\section{The use Abacus and Bundle of sticks in Addition}

Multi-digit addition and subtraction is one aspect of number development that has a tremendous representation in the research literature, yet little consensus exists about the preferred instructional sequence for acquiring two- and three-digits addition.

It is important to distinguish between root counting, reciting number names in correct order and enumeration, a process which involves using the sequence of number names in one- toone correspondence with a group of objects to work out the answer to a "how many?" question. Prehistorically, mankind had a mathematical understanding of one-to-one correspondence (Brooks \& Smith, 1987; Rudman, 2007). Prehistoric mankind carved "mark" according to the amount of something in order to represent numeral information based on one-to-one correspondence. Adaptation occurs during the development of verbal counting, after children have learned the number and strategies involve which depend on each culture. Another significant epistemological view of this study is that, tools or materials may produce mathematics concept (Borba \& Villarreal, 2005). This notion is based on the idea that mathematics concepts are not an individual enterprise, and tools or materials which are essential element of mathematics concepts (Villarreal \& Borba, 2005).

The process of developing specific teaching techniques (Kidwell, Ackerberg-Hasting \& Roberts, 2008). Thus, diverse tools and materials might be related to various mathematics concepts and concrete materials in the past are useful to reveal how mathematics concepts have developed overtime. Revealing the past that lies behind Bundle of sticks and Abacus may help us understand how to reflect on a wide range of discussion about teaching numerical concepts to students.

The preliterate notation of numbers by rope concept of one-to-one corresponding, but also describe the concept of equal increment in increasing amount according to the numbers (Roberts, 2001). Unlike the current number system, which uses ten different symbols for each digit (0 to 9), "quipu" manufactures tangled several knots in a tight sequence to represent a digit. 


\section{METHODOLOGY}

\section{Research Design}

Research design describes the basic design used in the study and its application to the study. It refers to the researcher's overall plan for obtaining answers to the research questions. The research design used for the study was the action research which is a type of design used to solve classroom problem scientifically. It is normally conducted in a local setting. The researcher therefore in an attempt to find immediate solution to the problem, resorted to the use of action research design.

This action research was used to investigate critically into pupils' poor performance in mathematics and specifically in addition of two- and three-digit numbers.

It is possible to say that action research can be looked at as a professional knowledge (Burns 2011).

Action research is actually suitable for any person who wishes to improve his or her performance or any group or organization who hopes for doing the same. As a matter of fact, action research is widely used in education, especially by teachers who use it to improve their teaching although it has got some shortfalls. Action research is costly, time consuming and stressful to undertake since it involves a lot of activities such as planning, implementation and evaluation just to mention a few. It can also tend to be biased if personal feelings and sentiments are not well controlled.

\section{Population of the Study}

The target population was Basic Two (2) Pupils of Ghana National College Basic School. It consisted of thirty-four (34) pupils comprising of eighteen (18) girls and sixteen (16) boys. This school was chosen because the researcher was on teaching practice program in that very school and was teaching at Basic Two (2).

\section{Sample and Sampling Technique}

An individual inventory evaluation test conducted by the researcher revealed that twenty (20) pupils out of the thirty-four (34) could add two- and three-digits numbers while fourteen (14) pupils consisting of eight (8) boys and six (6) girls were not able to do the addition. The fourteen (14) pupils scored below 50\% of the total marks. The intention here was to determine their level as well as specific skills in which they are deficient at. The fourteen (14) pupils who could not do simple addition of two- and three-digits numbers were chosen as sample for the project work.

The sampling technique for the study was purposive sampling technique. This is because the problem identified was based on pupils written exercises, visual observation and test on additions of two- and three-digit numbers.

\section{Research Instrument}

The researcher used observation and evaluation test as the main instruments to gather the relevant information for the study. 


\section{Observation}

Observation is the procedure whereby the researcher collects data on the current status of the subjects by watching, listening and recording what is being done by the target group. Observation was done during mathematics lessons. The researcher realized that most of the pupils were finding it difficult to add two- and three-digit numbers. Hence the researcher adopted the use of some selected instructional materials or teaching learning materials (TLMs) to assist the pupils to overcome the problem.

The purpose of the observation instrument helped the researcher at the intervention stag to determine the problem among the pupils. It also helped the researcher at the intervention stage to find out how the pupils apply the explanation and illustrations at their disposal.

Again, it helped at the post intervention or test to find out whether the intervention technique had any influence on pupils' approach in solving two- and three-digit numbers.

\section{Evaluation Test}

A test was conducted on Basic Two (2) Pupils of Ghana National College Basic School by the researcher to know the pupils understanding level of additions of two- and three-digit numbers with the using Abacus and Bundle of sticks to solve such problems.

\section{Pre-Test}

The Pre-Tests were conducted to diagnose the level of pupils' ability to add two- and threedigit numbers. This was done by giving pupils written test and oral exercise. From the result of the Pre-Test the researcher put the following interventions in place. See Appendices. Five questions were given to the pupils to be answered within twenty minutes in all cases.

Pre-Test was first (Pre-Test I) done for the thirty-four (34) pupils in the class of which fourteen (14) pupils consisting of eight (8) boys and six (6) were sampled for this study.

\section{Intervention}

Intervention is a set of strategies planned and implemented to solve a specific problem or improve on an educational practice located in an immediate situation. The main intervention used was the appropriate teaching learning materials or instructional materials under which the following activities were carried out: using Abacus to develop the place value concept and using Bundles of stick and "loose ones" to teach addition of two- and three-digit numbers involving.

\section{Activities}

\section{Activity one (1)}

\section{The use of Bundles of stick to teach addition of two-digit numbers}

In the first week, the researcher introduced pupils to the use of Bundles of stick and "loose ones" to enable them develop the skill of adding two- and three-digit numbers. For example, to add 25 and 18, researcher guided pupils to pick two bundles of sticks and 5 loose ones to represent 25 and pick one bundle and 8 loose ones to represent 18 . Then they first put the loose ones together and put the bundles also together to get the sum. Since the loose ones are 
13 and each bundle represents ten (10), they added to get 4 bundles and 3 loose ones as illustrated below.
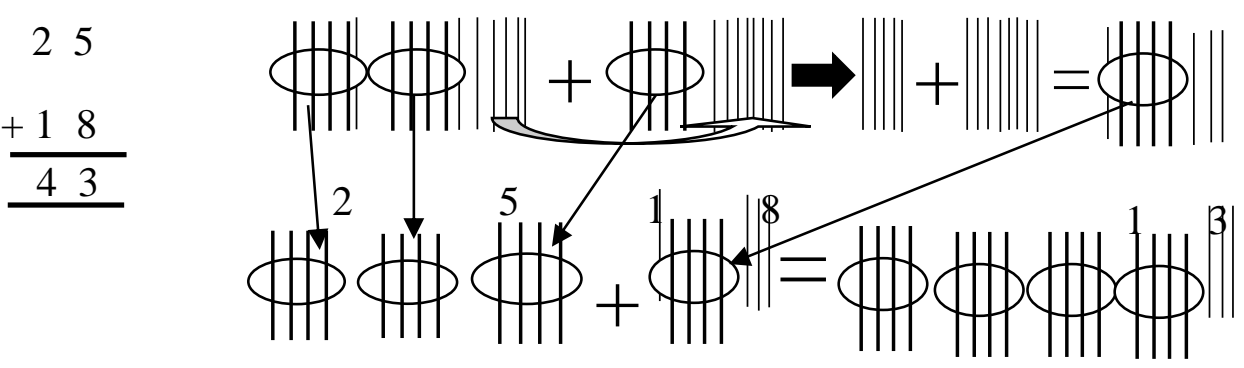

30

The ones were added up to give 13 which is one bundle (10 sticks) and three lose ones. After adding the three bundles (the tens), the exchanged one bundle was also added up to make it four (4) bundles and three (3) lose ones, which gave the sum of 43.

\section{Activity two (2)}

\section{The use of Abacus to teach addition of three-digit numbers}

During the intervention, various types of activities were used together with some teaching learning materials (TLMs) so as to make the lesson more practical and activity based to the learners. Example, using the Abacus to solve addition of 376 and 262. For 376, six beads were put on the ones column, seven beads were put on the tens column and three beads were put on the hundredth column. The same was done for the 262 where two beads were put on the ones column, six beads were put on the tens column and two beads were put on the hundredth column on the same Abacus.

The addition then started from the right end; 6 ones added to 2 ones gave 8 ones. On the tens column were 7 tens added to 6 tens which gave us 13 under the tens column. With the hundredth column, 3 was added to 2 to give us 5 under the hundredth column. We had 8 on the ones column, 13 on the tens column and 5 on the hundredth column. From the tens column, 1 (which is actually a hundred) was taken from the 13 and carried on to the hundredth column thus making the hundredth column 6 . It was therefore concluded that 376 added to 262 gives 638 , mathematically $376+262=638$. 


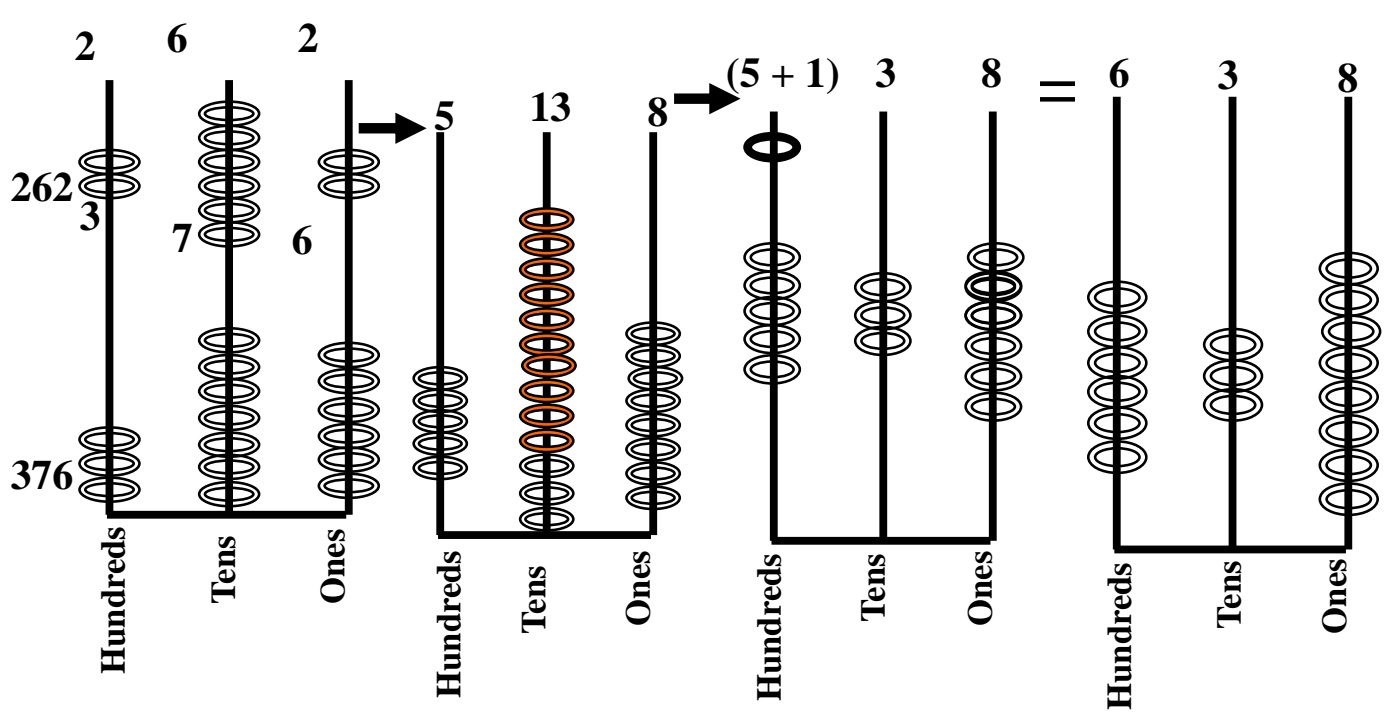

\section{Post-Test}

After the intervention, a Post-Test was conducted for the fourteen (14) pupils to either use the Abacus or the Bundle of sticks for solving some five questions within the same twenty (20) minutes as used in the Pre-Test. This was to see whether the interventions put in place had any positive effect on pupil's performances.

Questions were selected from Pupil's Mathematics Book 2. They were given about twenty minutes to solve the five-item problems. The researcher collected, marked and scored them accordingly. See Appendix 3.

\section{Data collection Process}

The researcher used observation and test to collect data for the problem. The researcher observed the pupils during mathematics lesson and saw that the pupils were finding it very difficult to solve addition problems involving place value during class exercises.

The researcher again selected some simple addition involving place value question from Pupil's Mathematics Textbook 2 to determine the extent of the problem. The researcher used a written test for both the Pre-Test and Post-Test conducted. The researcher used Abacus and Bundles of sticks as an intervention strategy to minimize their problem.

\section{Data Analysis plan}

The researcher used tables, charts, figures and percentage to analyze the data of the study. 


\section{RESULTS, FINDINGS AND DISCUSSIONS}

\section{Results}

The following data was collected for the Pre-Test I (for the thirty-four (34) pupils).

The researcher analyzed the outcome of the observation exercise undertaken at the beginning of the study. The researcher observed the pupil's performance in additions of two- and threedigit numbers when marking pupils class exercise and assignments. The researcher placed emphasis on the positions of numbers and the final answers provided and scored them out of ten (10) using simple percentages. The researcher analyzed the finding in the table below. See Appendix 1 - for the thirty-four (34) pupils.

\section{Pre-Test I Results}

Table 1: scores on pupils' knowledge in adding two- and three-digit numbers

\begin{tabular}{cccc}
\hline No. of pupils & Score ranges & Percentage $(\boldsymbol{\%})$ & Remarks \\
\hline $\mathbf{1 2}$ & $0-2$ & 35.29 & Lowest \\
$\mathbf{2}$ & $3-4$ & 0.06 & Low Average \\
$\mathbf{1 4}$ & $5-7$ & 41.18 & Average \\
$\mathbf{6}$ & $8-10$ & 17.65 & Above Average \\
$\mathbf{3 4}$ & $\mathbf{1 0}$ & $\mathbf{1 0 0}$ & Total \\
\hline
\end{tabular}

From Table I, the researcher gave out five (5) questions to the pupils which were marked over ten (10). Out of the ten (10) marks, twelve (12) pupils scored 0-2 marks representing 35.29\% and had the lowest mark. Two (2) of the pupils also scored 3-4 marks out of the total of ten (10) representing $0.06 \%$ which is low Average mark. Fourteen (14) scored from 5-7 marks representing $41.18 \%$. In all, only six (6) of the pupils which represent $17.65 \%$ scored marks from 8-10 which is the Above Average remarks.

The researcher purposively conducted the actual Pre-Test (Pre-Test II) for the Low Average and Lowest pupils of fourteen (14). The table below gives the detail representation of the results.

\section{Pre-Test II (for the fourteen (14) pupils)}

\section{Table 2: result of the Pre-Test (Pre-Test II) Addition of two- and three-digit numbers}

After the researcher had used test and observation to obtain information on pupils' possible cause of their inability to add two- and three-digits numbers, he further tested pupils to determine the extent of the problem. From the result in this test, Pre-Test II was analyzed in a simple percentage table below.

\begin{tabular}{cccc}
\hline No. of pupils & Scores range & Percentage (\%) & Remarks \\
\hline 13 & $0-2$ & 93 & Lowest \\
1 & $3-4$ & 7 & Low Average \\
0 & $5-7$ & 0 & Average \\
0 & $8-10$ & 0 & Above Average \\
\hline $\mathbf{1 4}$ & $\mathbf{1 0}$ & $\mathbf{1 0 0}$ & Total \\
\hline
\end{tabular}


The table above shows the results of the Pre-Test II conducted at the beginning of the study. It could be seen that only one (1) pupil scored the Low Average mark of 3 or 4 which is $7 \%$ with thirteen (13) pupils representing 93\% scoring between 0 and 2 marks which Lowest performance. And no one scored 5-7 and 8-10 marks. All the pupils sored below the average marks: an indication that their performance in mathematics was very poor.

\section{Post-Test I (results of the fourteen (14) pupils)}

\section{Table III: result of the Post-Test I on Addition of two- and three-digit numbers using} either the Abacus or the Bundles of stick.

After the Pre-Test II results, which indicated the poor performance of the pupils' inability to add two- and three-digit numbers correctly, the researcher adopted an intervention approaches which is the bundle of sticks to help minimize the problem. After the interventions, the researcher conducted another test on pupils to find out if there has been an improvement and the results was collected and presented on a table below as result of Post-Test I (See Appendix 3).

\begin{tabular}{cccc}
\hline No. of pupils & Scores range & Percentage $(\boldsymbol{\%})$ & Remarks \\
\hline 0 & $0-2$ & 0 & Lowest \\
0 & $3-4$ & 0 & Low Average \\
3 & $5-7$ & 21 & Average \\
11 & $8-10$ & 79 & Above Average \\
\hline $\mathbf{1 0}$ & $\mathbf{1 4}$ & $\mathbf{1 0 0}$ & Total \\
\hline
\end{tabular}

The table three (3) above provides the results of the Post-Test I conducted after the intervention. It could be seen that none of the pupils scored between 0-2, and 3-4 marks, three (3) pupil scored average marks between 5 and 7 which is $21 \%$ and eleven (11) pupils representing 79\% scored between 8 and 10 marks which is above average performance. In general, all the pupils scored the average marks and above. The result from the Post-Test I show clearly that there has been a great improvement in pupils' performance in mathematics after the intervention.

\section{Findings}

From the discussion of the data presented on table one (1) to three (3), if pupils have had enough time to practice on how to add two- and three-digit numbers where they have been assisted, supervised and motivated, addition and mathematics would become easier and more understandable.

There have been clear indications from the results obtained by adding two- and three-digits numbers through demonstrations, practical activities, games and motivations by beginners is the best and most convenient approach. Thus, through the various activities like the use of Bundle of stick and lose ones and Abacus to teach addition of two- and three-digits numbers.

Again, the results from all the evaluation exercises clearly showed that the activities designed for this study have really helped pupils to add two- and three-digit numbers. The differences of performance as in the Pre-Test II and Post-Test I with references to the number of pupils 
who scored lowest, below average, average and above average marks is an indication of improvement as can be seen in the Post-Test I. The performance of the pupils can now be inferred that the vast differences of their performance in the Post-Test I was brought about as a result of the intervention strategies employed by the researcher.

\section{Graph comparism of the Pre-Test II and the Post-Test I}

$\begin{array}{ccc}\text { Marks (10) } & \text { Pre-Test II } & \text { Post-Test I } \\ 0-2 & 13 & 0 \\ 3-4 & 1 & 0 \\ 5-7 & 0 & 3 \\ 8-10 & 0 & 11\end{array}$

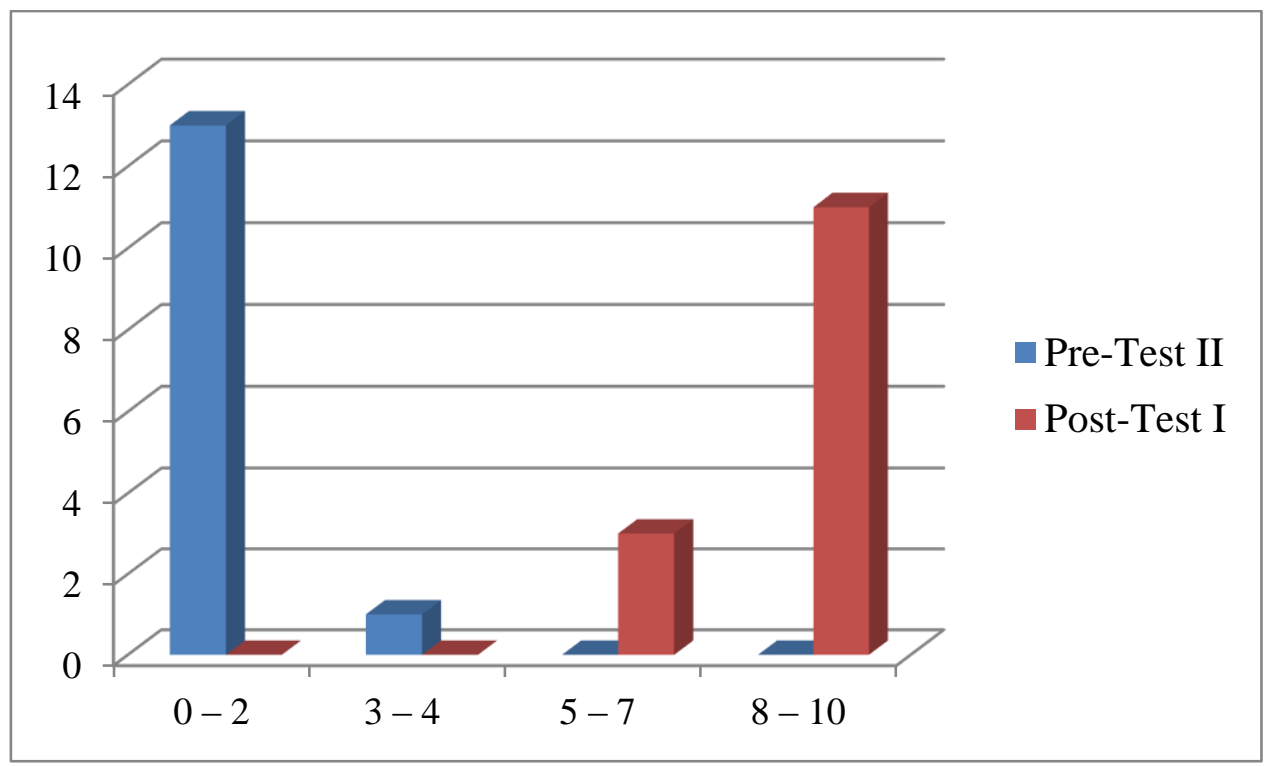

Figure 1: Comparism of the Pre-Test II and the Post-Test I

\section{SUMMARY, CONCLUSIONS AND RECOMMENDATIONS}

\section{Summary of the Findings}

The study findings show that Abacus and Bundle of sticks are effective in reinforcing acquisition of addition of two- and three-digit numbers. The Basic Two (2) Pupils of Ghana National College Basic School that were taking through the use of Abacus and Bundles of stick during mathematics lessons had more of the pupils attempting the test administered to them.

This shows that using Bundle of sticks and Abacus reinforce acquisition of adding two- and three-digit numbers skills. The study established that the schools do not have enough teaching and learning materials to be used in teaching and learning mathematics concepts especially addition of two- and three-digit numbers. 
The study also established that the pupils that had the chance to use the Abacus and Bundles of stick performed well in addition of two- and three-digit numbers exercise given.

Abacus and Bundles of stick promote acquisition of addition skills (addition of two- and three-digit numbers). The adoption of the methods by the researcher helped them to acquire skills, knowledge and better understanding of the concept addition, apparently since majority of the pupils performed creditably, the researcher can firmly say that his purpose to Basic Two (2) pupils of Ghana National College Basic School to add two- and three-digit numbers was achieved.

\section{Conclusion}

The study which sought to teach addition of two- and three-digit numbers was conducted at Ghana National College Basic School among Basic Two (2) Pupils in the Cape Coast Metropolitan. The study tried to intervene by instituting strategies to enhance it through various activity organized to arrive at improving pupils knowledge in additions, the researcher is of the firm conviction that the study was worth time spent and timely too.

\section{Recommendations}

The following recommendations were made as the result of the outcome of the study:

- Enough and appropriate teaching learning materials should be used by teachers or educators to make pupils full participation and develop interest in place value concept and mathematics as a whole.

- The Ghana Education Service (GES) should organize a regular in-service training for teachers on the concept place value especially at basic level.

- Teachers having similar problems could adopt the use of Abacus, Multi-Base Block and Bundles of stick as method to solve their problems.

- Teachers should place more emphasis on hand on concept or activities on the teaching of two- and three-digit numbers so that the pupils can grasp the concept with ease as children learn best by doing and active involvement.

\section{REFERENCES}

Acha, C. K. (2014). Trend and levels of women empowerment in Nigeria. American Journal of Applied Mathematics and Statistics, 2(6), 402-408.

Addae, B. D., 81 Agyei, D. D. (2018). Students' attitudes towards the study of mathematics and their perceived teachers' teaching practices. European Journal of Educational and Development Psychology, 6(2), 1-14.

Ansubel, J. H., Meyer, P. S., \& Yung, J. W., (2003). A primer on logistic growth and Substitution: the mathematics of the Log let Lab software. Technological Forecasting and Social Change, 61(3), 247-271.

Apronti, D. (2001). Primary Mathematics, Bayoba Ltd, Kumasi. Ausubel, Asante, K. O. (2012). students' attitudes towards mathematics. IFE Psychologia: An International Journal, 20(1), 121-133. 
Benjamin, S. (2002). The mathematics of Inclusive Education an Ethnography.

Biggs E. (2000), Teaching Mathematics 5 to 9 Britain, Library Cataloguing in Publication data

Davidson, A. (2001). The Priorities and Challenges of Primary Teachers' Knowledge in Their Mathematics Planning. Mathematics Education Research Group of Australasia.

Forman, E. A. (2003). A sociocultural approach to mathematics reform: Speaking, Inscribing, and doing mathematics within communities of practice. In J. Kilpatrick, W.

Hubbard, T. W. (2000). Teaching aid for hair setting and coloring. U. S. Patent No. 4,224,745, Washington DC: Patent and Trademark Office.

Kaiejaiye, A. O. (2004). Teaching Primary Mathematics. Longman.

Land F. (2002), the Language of Mathematics, Britain, Murray John Publishers Ltd.

National Council of Teachers of Mathematics. (2007). Mathematics teaching today: Improving practice, improving student learning (2nd ed.). Reston, VA: Author.

Oxford Learner's Advance Dictionary (2001).

Pal, C. (2009). Dynamic system identification by neural network: a new, fast learning method based on error back propagation. Journal of intelligent material systems and structures, $5(1), 127-135$.

Ubuz, B. (2009). Interpreting a graph and constructing its derivative graph: stability and change in students' conceptions. International Journal of Mathematical Education in Science and Technology, 38(5), 609-637. 


\section{APPENDICES}

\section{APPENDIX 1}

\section{PRE-TEST I (for the thirty-four (34) pupils)}

Solve the following question by adding living your answers in hundreds, tens and ones

1. 137

$+43$

2. 462

$+37$

3. 291

$+72$

4. 832

$+16$

5. 653

$+16$ 


\section{APPENDIX 2}

\section{PRE-TEST II (for the fourteen (14) pupils)}

Solve the following question by adding living your answers in hundreds, tens and ones

1. $724+73=$

2. $536+91=$

3. $727+145=$

4. $264+161=$

5. $219+356=$

\section{APPENDIX 3 \\ POST-TEST}

Using either the Abacus or the Bundles of stick, regroup and solve the following question and write your answers in hundreds, tens and ones:
1. $316+20=$
2. $295+32=$
3. $456+12=$
4. $158+86=$
5. $891+32=$

Copyright (C) 2020 The Author(s). This is an Open Access article distributed under the terms of Creative Commons Attribution-NonCommercial-NoDerivatives 4.0 International (CC BYNC-ND 4.0), which permits anyone to share, use, reproduce and redistribute in any medium, provided the original author and source are credited. 